\title{
Comparative Effectiveness and Safety of Allografts and Autografts in Posterior Cruciate Ligament Reconstruction Surgery: A Systematic Review
}

\author{
Cecilia de Villiers, M.Sc., B.Sc., Gregor Goetz, M.S.Sc., M.P.H., \\ Patrick Sadoghi, M.D., Ph.D., M.B.A., and \\ Sabine Geiger-Gritsch, D.M.Sc., M.H.Sc., M.Pharm
}

\begin{abstract}
Purpose: To evaluate the evidence of the effectiveness and safety of allografts compared to autografts in posterior cruciate ligament reconstruction. Methods: Four electronic databases were systematically searched for eligible randomized controlled studies. Crucial effectiveness outcomes included patient-reported function, activity level and symptoms, clinical knee stability, health-related quality of life, and patient satisfaction. Safety was evaluated through graft failures, revisions, reruptures and complications. The internal validity of the studies was assessed by the Cochrane risk of bias tool, and the strength of the evidence was judged according to the Grading of Recommendations, Assessment, Development and Evaluation (GRADE). Results: Two randomized controlled studies were included: 50 patients were analyzed in the allograft group and 58 in the autograft group. No statistically significant postoperative differences were reported between the groups for patient-reported function, activity levels or symptoms. One study reported a statistically significant difference in instrumented postoperative anteroposterior knee laxity favoring stability in autografts. This difference is, however, not relevant in the clinical setting. Insufficient evidence was found to judge safety outcomes and because complications were poorly measured, and none of the studies reported on graft failure, revision or rerupture rates. The studies were judged with unclear to high risk of bias. The strength of the evidence for effectiveness and safety was judged to be low to very low, according to GRADE. Conclusions: Allografts may be comparable to autografts for crucial effectiveness outcomes, but insufficient evidence was found to judge crucial safety outcomes due to poor reporting of safety measures and outcomes. Results should be interpreted with caution because there is lack of good-quality evidence to support the superiority of allografts over autografts due to the high risk of bias in the primary studies and overall very low strength of the body of evidence according to GRADE. Level of Evidence: Systematic review of Level II studies.
\end{abstract}

A n annual incidence rate of 2 cases per 100,000 individuals is reported for isolated posterior cruciate ligament ruptures. ${ }^{1}$ Historically, a conservative

From the HTA Austria - Austrian Institute for Health Technology Assessment GmbH (Former: Ludwig Boltzmann Institute for Health Technology Assessment), Vienna, Austria (C.d.V., G.G., S.G.-G.); and Department of Orthopaedics and Trauma, Medical University of Graz, Graz, Austria (P.S.).

The authors report that they have no conflicts of interest in the authorship and publication of this article. Full ICMJE author disclosure forms are available for this article online, as supplementary material.

Received December 11, 2019; accepted July 30, 2020.

Address correspondence to Cecilia de Villiers, M.Sc., B.Sc., HTA Austria Austrian Institute for Health Technology Assessment GmbH (Former: Ludwig Boltzmann Institute for Health Technology Assessment), Garnisongasse 7/Top 20,1090, Vienna, Austria.E-mail: cila.devilliers@gmail.com

Published by Elsevier Inc. on behalf of the Arthroscopy Association of North America. This is an open access article under the CC BY-NC-ND license (http://creativecommons.org/licenses/by-nc-nd/4.0/).

2666-061X/191489

https://doi.org/10.1016/j.asmr.2020.07.017 management approach has been followed and because of the intrinsic healing capability of the PCL, ${ }^{2}$ surgical intervention has been reserved mainly in the event of failed conservative management or for the treatment of

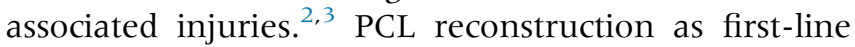
routine care is still debated ${ }^{4}$ because surgical intervention is not without its own challenges; there is a reported graft failure rate of $11.6 \%$ (range of $2.3 \%$ $30 \%)^{5}$ and a revision rate of $12.6 \%$ in a highly active military population. ${ }^{6}$ Complications such as rerupture or graft failures due to technical errors, including poor graft size, inadequate graft strength and improper placement of the tibial or femoral tunnels, ${ }^{7,8}$ have been reported. Significant improvements were observed in post-PCL reconstruction functional scores and knee stability, although this seems to be valid only for moderate levels of activity and a fair return to sport level. ${ }^{9}$ A careful consideration of surgical-intervention decisions should, therefore, include multiple factors, 
such as the patient's level of activity, the functional demands on the knee, the surgeon's experience, and the presentation of other associated meniscal or ligament injuries. ${ }^{2}$

The graft type to be used is a further decision to consider because autografts and allografts are potential sources of PCL reconstructions. The chosen graft should resemble the original PCL anatomy, taking into consideration that each graft is associated with different benefits and limitations. Autografts do not generally pose the risk of rejection or disease transmission, although they are associated with longer surgical times, postoperative donor-site pain and morbidity and weakness of the donor extensor or flexor muscle groups. ${ }^{10}$ Allografts provide an alternative, but they are associated with their own limitations, including potential graft rejection, disease transmission $^{11}$ and weakening of the graft structure as a result of the sterilization process. ${ }^{2,12}$ This increases the potential risk of delayed healing, remodeling and integration of the graft; tunnel widening, cyst formation and effusions have been reported. ${ }^{11,13}$ Limited graft availability and the associated costs are also factors to consider with the choice of allograft. ${ }^{2}$

The current literature concerning systematic reviews reports postoperative improvement of clinical and patient-reported outcomes following PCL reconstructions in both allograft and autograft groups. ${ }^{12,14,15}$ Controversy remains in regard to whether 1 graft type provides better outcomes and is superior to the other in PCL reconstruction. ${ }^{16}$ The purpose of this study was to evaluate the effectiveness and safety evidence of allografts compared to autografts in PCL reconstructions. The authors evaluated the hypothesis that the effectiveness and safety outcomes of allografts are superior compared to those of autografts in PCL reconstruction.

\section{Methods}

This systematic review was based on the European Network of Health Technology Assessment (EUnetHTA) Core Model domains (version 3.0) ${ }^{17}$ and was reported via the Preferred Reporting Items for Systematic Reviews and Meta-Analyses (PRISMA) guidelines. ${ }^{18,19}$ The project was commissioned by the Austrian Ministry of Health as part of the decision support series ${ }^{20}$ for Health Technology Assessments.

The systematic literature and hand searches described below were used to identify relevant studies according to the Population, Intervention, Comparator, Outcomes and Study Design (PICOS). ${ }^{20}$ Randomized controlled trial (RCT) study designs are deemed the best evidence for evaluating effectiveness and safety in Health Technology Assessments reports because of their robust internal validity and low risk of bias. ${ }^{21}$ The original systematic literature search was performed in 2018. A recent updated manual search in the PubMed database as well as the Arthroscopy.com search function did not identify any additional eligible studies for inclusion between 2019 and 2020.

\section{Literature Search Strategy}

The Medline via Ovid, Embase, the Cochrane Library and Centre for Reviews and Dissemination electronic databases were systematically searched for eligible studies published from inception to December 2018. Eligible clinical trials and articles published in English or German were identified, and no other screening criteria were applied. A preceding hand search in PubMed identified published systematic reviews and metaanalyses, and their reference lists were used to identify additional relevant RCTs. All of these primary studies were also captured in the literature search, and any duplications were removed. ${ }^{20}$ Three clinical trials registers were also searched. The original search was broad and included studies of the anterior cruciate ligament according to the commissioned project. Only the PCL reconstruction studies were selected as per the PRISMA diagram in Fig 1.

\section{Study Eligibility, Inclusion and Exclusion Criteria and Study Selection}

The inclusion criteria were in accordance with the study PICOS. ${ }^{20}$ Patients who were eligible for PCL reconstruction, revision PCL reconstruction or PCL reconstruction as a result of multiligament knee injuries were included and compared in terms of crucial effectiveness and safety outcomes to other techniques of PLC reconstruction, such as autograft, synthetic graft and conservative management. For the purpose of this study, the focus was on PCL reconstruction. Revision PCL reconstruction and PCL reconstruction as a result of multiligament knee injuries were excluded due to the lack of evidence found to either support or reject the superiority of allografts over autografts. ${ }^{20}$

RCTs were the chosen study design, ${ }^{21}$ with prospective, comparative cohort studies to be considered if no RCTs were available. Three authors (GG, SGG, CDV) conducted the study selection, and 2 authors (GG, SGG) screened the abstracts. The full-text screening was conducted by 2 authors (GG, CDV), and the third author (SGG) was consulted for consensus in the event of any unresolved discrepancies.

\section{Outcome Measures}

The following crucial outcomes were chosen in accordance with the Grading of Recommendations, Assessment, Development and Evaluation (GRADE) guidelines $^{22}$ to evaluate the relative effectiveness of allografts compared to autografts in PCL reconstruction: patient-reported function, activity levels and symptoms measured using validated instruments, such as the 

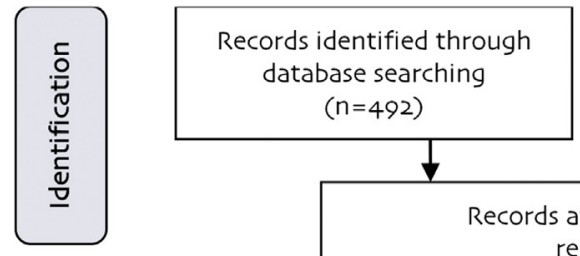

Additional records identified through other sources $(n=492)$

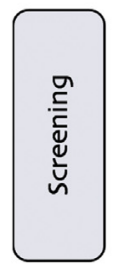

Records after duplicates

removed

$(n=492)$

Fig 1. PRISMA diagram

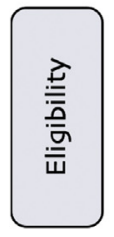

$$
(n=13)
$$
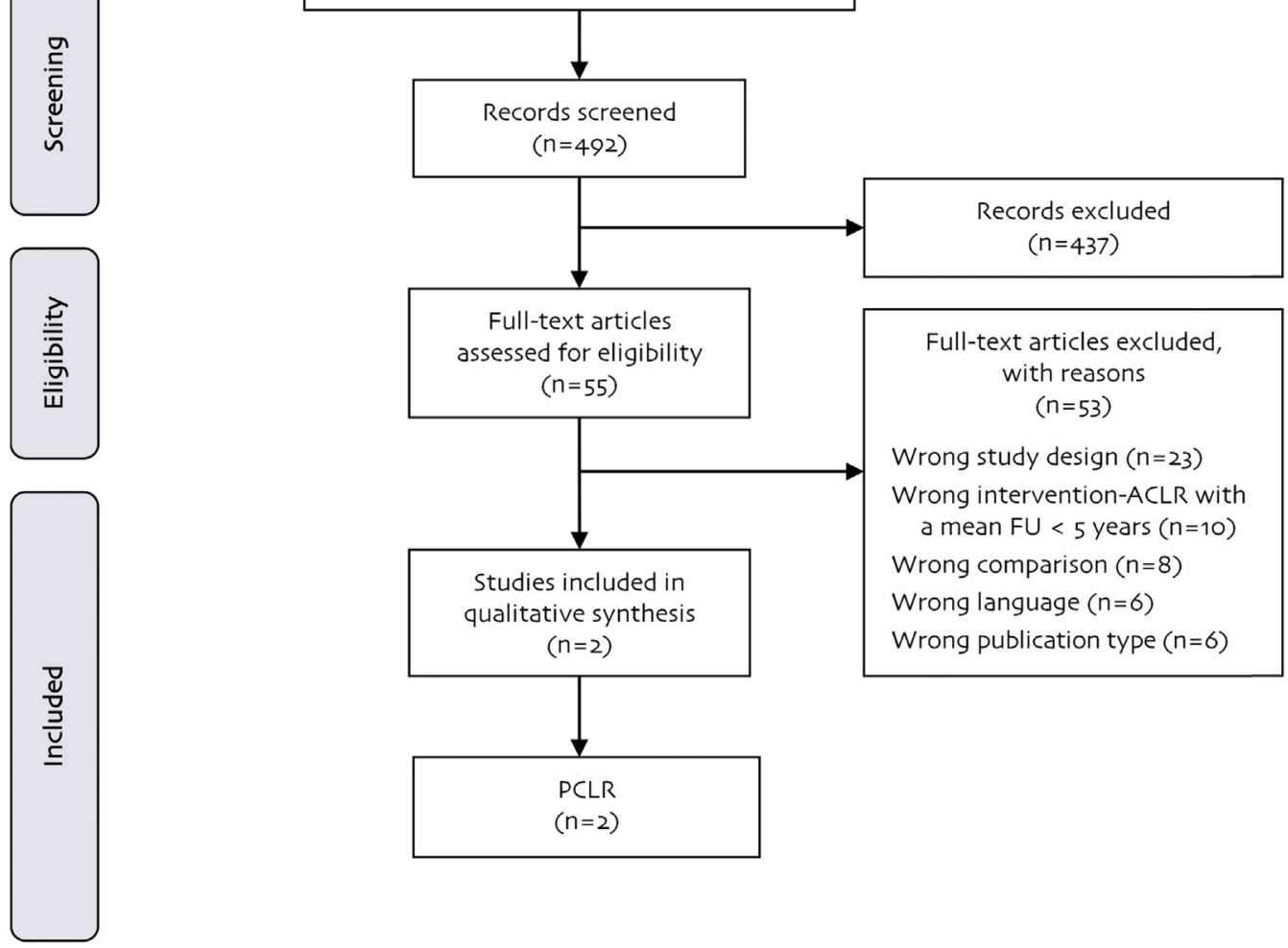

Lysholm score, the Tegner score and the subjective part of the International Knee Documentation Committee (IKDC) scores.

Clinical knee stability measured by a validated instrument, such as the KT-1000 arthrometer and the reverse Lachman and Pivot shift tests, and healthrelated quality of life and patient satisfaction, as measured by validated instruments, were included as important outcomes but were not crucial for the assessment.

The crucial outcomes included to evaluate safety were graft failures, reruptures, reoperations and revisions, complications, and procedure-related mortality. Graft failures were chosen because they could result in further or revision surgery; however, it was not defined in a standardized way by the included studies. Reruptures, reoperations and revisions are synonyms for graft failures and were extracted separately. Complications were broad and included surgical complications, such as infection, anesthesia complications and complications associated with cruciate ligament surgery, such as postoperative loss of motion, arthrofibrosis and donor site morbidity.

\section{Data Extraction}

Pre- and postoperative data were systematically extracted from the included studies. A single extraction method was used by 1 author, and a second author controlled the extracted data. Disagreements were resolved through discussion or in consultation with a third author. Table 1 summarizes the level of evidence $^{23}$ of the 2 included studies. The extraction table (Table 2) was populated with variables according to the PICOS study. This included the author, the year of publication, the study design, the intervention and comparators, the surgical procedure with study inclusion and exclusion criteria, the rehabilitation post surgery, the number of patients, their ages, sex, mean follow-up, loss to follow-up, and other patients' characteristics. Crucial effectiveness outcomes included patient-reported function, activity levels and symptoms and clinical knee stability. Crucial safety outcomes 
Table 1. Level of Evidence ${ }^{23}$

\begin{tabular}{|c|c|c|}
\hline Study & Level of Evidence & Investigators \\
\hline $\begin{array}{l}\text { Prospective randomized comparison of knee } \\
\text { stability and proprioception for posterior cruciate } \\
\text { ligament reconstruction with autograft, hybrid } \\
\text { graft and gamma-irradiated allograft }\end{array}$ & Level II & $\begin{array}{l}\text { Li, Jia (author) } \\
\text { Kong, Fanlong (author) } \\
\text { Gao, Xianda (author) } \\
\text { Shen, Yong (author) } \\
\text { Gao, Shijun (author) }\end{array}$ \\
\hline $\begin{array}{l}\text { Comparison of autogenous and allogenous } \\
\text { posterior cruciate ligament reconstruction of the } \\
\text { knee }\end{array}$ & Level II & $\begin{array}{l}\text { Wang, Ching-Jen (author) } \\
\text { Chan, Yi-Sheng (author) } \\
\text { Weng, Lin-Hsiu (author) } \\
\text { Yaun, Li-Jen (author) } \\
\text { Chen, Han-Shiang (author) }\end{array}$ \\
\hline
\end{tabular}

included graft failure rates, reruptures, revisions, overall complications, and other complications.

\section{Study Quality Appraisal}

The Cochrane Risk of Bias Tool ${ }^{24}$ was used to assess the internal validity of the individual RCT studies. Two authors assessed the risk of bias independently, and any discrepancies were resolved through discussion. A third author was consulted if no consensus was reached.

Only postoperative data from the extraction tables were synthesized according to the GRADE ${ }^{22}$ methodology. Each outcome was individually judged according to the study design, risk of bias, inconsistency, indirectness, imprecision, and other considerations. The preoperative scores were excluded from the synthesis because the primary studies reported mainly the postoperative differences for the comparison between the allograft and autograft groups.

\section{Data Synthesis}

A qualitative synthesis of the evidence describes the comparison between allografts and autografts in PCL reconstruction. No statistical analysis could be performed, and no results were pooled in a meta-analysis due to clinical outcomes and methodologic heterogeneity.

\section{Results}

\section{Study Selection and Characteristics}

The PRISMA diagram (Fig 1) shows the study selection process. Four hundred ninty-two records were identified and screened resulting in 55 full-text articles assessed for eligibility. Fifty three articles were excluded because of wrong study design, wrong intervention, wrong comparison, wrong language, or wrong publication type. Two of the RCTs included compared allografts to autografts in PCL reconstruction. ${ }^{25,26}$ Different types of allografts were used; 1 study reported the use of 4-stranded, y-irradiated tibialis anterior tendon allografts, ${ }^{25}$ and the other study used Achilles tendon and anterior tibial tendon allografts. ${ }^{26}$

Table 2 summarizes the data extraction and study characteristics of the 2 included studies, in which 145 patients from both studies were included; 30 patients received hybrid grafts, and 7 were lost to follow-up. The analysis included 108 patients: $\mathrm{n}=50$ in the allograft group and $\mathrm{n}=58$ in the autograft group. The mean follow-up time was 2.8 years in the study by Wang et al. $^{26}$ and 5.6 years in the study by Li et al. ${ }^{25}$ The mean age in the groups was 32.2 (allografts) versus 31.3 (autografts) years ${ }^{25}$ and 30 (allografts) versus 29 years (autografts). ${ }^{26}$

The study by $\mathrm{Li}$ et $\mathrm{al}^{25}$ reported inclusion criteria, such as persistent posterior laxity greater than or equal to grade 2, lack of response to medical and physical conservative treatment for more than 3 months, and PCL rupture identified by magnetic resonance imaging. The Wang et al. study ${ }^{26}$ did not report any inclusion criteria. During the PCL reconstruction procedure, meniscal injuries were addressed, and patients received pre- and postsurgical rehabilitation such as physiotherapy. The studies reported patients' receiving the same postsurgical rehabilitation program; however, only the study by Li et al. ${ }^{25}$ specified it as inclusive of a functional brace (6-12 weeks), passive range-of-motion exercises, progressive weight bearing after 2 weeks, and closed kinetic chain exercises. Only the study by Wang et al. ${ }^{26}$ used radiographs for postoperative follow-up to measure the tibial and femoral tunnel widening, alignment of the knees and degenerative changes. The authors also reported a mild to moderate posterior laxity in $25 \%$ of patients for both groups, but the laxity grades were not quantified, nor was it reported how the laxity was assessed.

\section{Quality Appraisal of the Evidence}

\section{Risk of bias assessment within PCL reconstruction studies}

The two RCT studies were assessed for individual risk of bias according to the Cochrane Risk of Bias Tool. ${ }^{24}$ Fig 2 represents the risk of bias as being unclear to high at the study level. The unclear risk was due to the incomplete description of the randomization process in the study by Li et al. ${ }^{25}$ The risk for performance bias was unclear in both studies because of the lack of 
Table 2. Data Extraction Table

\begin{tabular}{|c|c|c|}
\hline & \multicolumn{2}{|l|}{ Author, year } \\
\hline & Li $2016^{25}$ & Wang $2004^{26}$ \\
\hline Country & China & Taiwan \\
\hline Interventions/Products & 4-stranded y-irradiated tibialis anterior tendon allograft & $\begin{array}{l}\text { Allograft (incl. Achilles tendon and } \\
\text { anterior tibial tendons) }\end{array}$ \\
\hline Comparator & $\begin{array}{l}\text { Gracilis and semitendinosus tendon autograft } \\
\text { Hybrid graft (y-irradiated tibialis anterior tendon allograft } \\
\text { and semitendinosus tendon autograft) }\end{array}$ & $\begin{array}{l}\text { Autograft (incl. quadriceps tendon- } \\
\text { patellar bones and quadruple } \\
\text { hamstrings) }\end{array}$ \\
\hline Number of patients & $90^{*}$ & 55 \\
\hline & 30 vs 30 vs 30 & 23 vs 32 \\
\hline Inclusion criteria & $\begin{array}{l}\text { Persistent posterior laxity greater than or equal to grade } 2 \text {, } \\
\text { Lack of response to conservative treatment (medication and } \\
\text { physical therapy) for more than } 3 \text { months } \\
\text { Objective evidence of PCL rupture by MRI. }\end{array}$ & $\mathrm{NR}^{\dagger}$ \\
\hline $\begin{array}{l}\text { Rehabilitation (before or after } \\
\text { PCLR) }\end{array}$ & $\begin{array}{l}\text { The } 3 \text { groups of patients followed the same postoperative } \\
\text { rehabilitation program. } \\
\text { Physiotherapy } \\
\text { Rehabilitation outside the hospital was not controlled. }\end{array}$ & $\begin{array}{l}\text { Patients received the same } \\
\text { postoperative rehabilitation (incl., } \\
\text { e.g., exercise, functional knee } \\
\text { braces, etc.). } \\
\text { Physiotherapy: NR }\end{array}$ \\
\hline $\begin{array}{l}\text { Age of patients, mean } \pm \mathrm{SD} \\
\text { (range), yrs }\end{array}$ & $\begin{array}{l}32.2 \pm 7.8(20-40) \text { vs } 31.3 \pm 6.2(20-40) \text { vs } 30.6 \pm 7.5(20- \\
40)^{\S}\end{array}$ & $30 \pm 12(16-64)$ vs $29 \pm 12(16-54)$ \\
\hline Sex, n female $(\%)$ & $11(40.7)$ vs $9(34.6)$ vs $10(37)^{\S}$ & 7 (30.4) vs $7(21.9)$ \\
\hline $\begin{array}{l}\text { Further relevant patient } \\
\text { characteristics }\end{array}$ & $\begin{array}{l}\text { Patients with meniscal tears underwent partial } \\
\text { meniscectomies (if irreparable) or repairs. } \\
\text { No. of patients with no treatment of meniscal tears: } \\
10 / 30 \text { patients }(33.3 \%) \text { vs } 9 / 30 \text { patients }(30 \%) \text { vs } 9 / 30 \\
\text { patients }(30 \%) \text {; diff. n. s. }\end{array}$ & $\begin{array}{l}\text { Associated injuries were treated } \\
\text { accordingly before PCLR. } \\
\text { Concomitant treatments : } \\
5 \text { meniscectomies } \\
3 \text { meniscal repairs } \\
3 \text { debridements for chondral } \\
\text { lesions }\end{array}$ \\
\hline $\begin{array}{l}\text { Lysholm score, mean } \pm \mathrm{SD} \\
\quad \text { (range) }\end{array}$ & $\begin{array}{l}\text { Preoperative: } \\
\quad 64.1 \pm 10.8 \text { vs } 63.8 \pm 11.2 \text { vs } 62.3 \pm 12.9 \text {; diff. n. s. with } \\
\mathrm{P}=0.721 \\
\text { Postoperative }^{\dagger \dagger} \text { : } \\
85.2 \pm 3.9 \text { vs } 87.8 \pm 3.6 \text { vs } 86.9 \pm 4.3 \text {; diff. n. s., with } \mathrm{P}= \\
0.193\end{array}$ & $\begin{array}{l}\text { Preoperative: NR } \\
\text { Postoperative }{ }^{\ddagger} \\
92.3 \pm 6.8 \text { vs. } 87.8 \pm 9.6 \text {; diff. n. s., } \\
\text { with } \mathrm{P}=0.077\end{array}$ \\
\hline Tegner score, mean \pm SD & $\begin{array}{l}\text { Preoperative: } \\
2.6 \pm 1.1 \text { vs } 2.7 \pm 1.2 \text { vs } 2.9 \pm 1.3 \text {; diff. n. s., with } \mathrm{P}= \\
0.662 \\
\text { Postoperative }{ }^{\dagger \dagger} \\
6.2 \pm 1.7 \text { vs } 6.8 \pm 1.1 \text { vs } 6.5 \pm 1.8 \text {; diff. n. s., with } \mathrm{P}= \\
0.096\end{array}$ & $\begin{array}{l}4.70 \pm 1.66 \text { vs } 4.73 \pm 1.66 \text {; diff. n.s., } \\
\quad \text { with } \mathrm{P}=0.976\end{array}$ \\
\hline $\begin{array}{l}\text { IKDC score (subjective), mean } \pm \\
\text { SD (range) }\end{array}$ & $\begin{array}{l}\text { Preoperative: } \\
\quad 65.9 \pm 9.3 \text { vs } 66.5 \pm 10.1 \text { vs } 65.5 \pm 11.5 \text {; diff. n. s., with } \\
\mathrm{P}=0.586 \\
\text { Postoperative } \mathrm{e}^{\dagger \dagger} \\
80.2 \pm 6.8 \text { vs } 83.5 \pm 6.3 \text { vs } 82.8 \pm 5.7 \text {; diff. n. s., with } \mathrm{P}= \\
0.153\end{array}$ & NR \\
\hline
\end{tabular}


Table 2. Continued

\begin{tabular}{|c|c|c|}
\hline & \multicolumn{2}{|l|}{ Author, year } \\
\hline & $\mathrm{Li} 2016^{25}$ & Wang $2004^{26}$ \\
\hline \multicolumn{3}{|l|}{ Clinical knee stability } \\
\hline Lachman test (grade $0-1)$, n ( \%) & NR & $\begin{array}{l}\text { Reverse Lachman } \\
\text { Preoperative: NR } \\
\text { Postoperative }{ }^{\ddagger+} \text { mean } \pm \text { SD } \\
(\text { range })^{\S \S}: \\
0.70 \pm 0.56(0-2) \text { vs } 0.75 \pm 0.67 \\
(0-3) \text {; diff. n. s., with } \mathrm{P}=0.898\end{array}$ \\
\hline Pivot shift test (grade $0-1)$, n ( $\%)$ & $\begin{array}{l}\text { Reverse Pivot shift (postoperative at final FU): } \\
26(96.3) \text { vs } 26(100) \text { vs } 27 \text { (100); diff. n. s., with } \mathrm{P}=0.407\end{array}$ & NR \\
\hline $\begin{array}{l}\text { Side-to-side difference in } \mathrm{mm}, \\
\text { mean } \pm \mathrm{SD} \text { (range) }\end{array}$ & $\begin{array}{l}\text { Measured with Instrumented Anteroposterior Measurements } \\
\text { Postoperative: } \\
3.5 \pm 1.1\left(\mathrm{NR}^{\|\|}\right) \text {vs } 2.1 \pm 1.0\left(\mathrm{NR}^{\text {Iף }}\right) \text { vs } 2.6 \pm 1.2(\mathrm{NR} \#) \text {; } \\
\text { diff. s. s., with } \mathrm{P}<0.001\end{array}$ & $\begin{array}{l}\text { Measured with the KT-1000 } \\
\text { arthrometer } \\
\text { Preoperative: NR } \\
\text { Postoperative***: } \\
2.83 \pm 1.70(1-6) \text { vs } 3.16 \pm 2.60 \\
\text { (1-10); diff. n. s., with } \mathrm{P}=0.605\end{array}$ \\
\hline $\begin{array}{l}\text { IKDC score (objective; normal and } \\
\text { nearly normal), n }(\%)^{\dagger \dagger \dagger}\end{array}$ & $\begin{array}{l}\text { Postoperative (at Final FU): } \\
\qquad 24 \text { (88.9) vs } 25 \text { (96.2) vs } 25 \text { (92.6); diff. n. s., with } \mathrm{P}=0.716\end{array}$ & $\begin{array}{l}\text { Preoperative: NR } \\
\text { Postoperative }{ }^{+\neq} \text {: } \\
14(60.9) \text { vs } 23 \text { (71.9); diff. n. s., } \\
\text { with } \mathrm{P}=0.391\end{array}$ \\
\hline \multicolumn{3}{|l|}{ Safety Outcomes } \\
\hline Reoperation rate, n (\%) & $\begin{array}{l}\text { The study stated that no patient needed additional surgery } \\
\text { because of recurrent or residual posterior laxity. }\end{array}$ & NR \\
\hline Overall complications, n (\%) & NR & $0(0)$ vs $7(21.9)$ \\
\hline Infection, n (\%) & The study stated that no postoperative infection occurred. & $0(0)$ vs $2(6.3)^{\S \S \S}$ \\
\hline Other complications & $\begin{array}{l}\text { Regarding complications, the study reported that there were } \\
\text { no cases of major neurovascular, infectious, vascular, deep } \\
\text { venous thrombosis, or wound complications. }\end{array}$ & 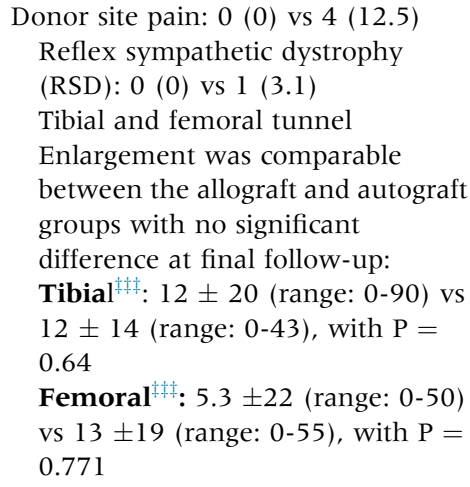 \\
\hline
\end{tabular}

*116 points were assessed for eligibility. Of those, 90 points were randomized in the 3 treatment groups.

${ }^{\dagger}$ The study reported only that it consisted of patients who underwent PCL reconstruction. In this context, the study states that the indication for surgery included pain and instability because of high-energy posterior cruciate ligament injury with failure of conservative treatments for 3 months.

${ }^{\ddagger}$ Postoperative physiotherapy may have included, but was not limited to, the following: a functional brace (6-12 weeks), passive range of motion exercises, progressive weight bearing after 2 weeks, and closed kinetic chain exercises.

${ }^{\S}$ The study reported on demographic data using the analyzed (not the enrolled) patients. Therefore, the denominator(s) are the analyzed patients within the groups.

"Differences between treatment groups were not reported.

The overall mean was calculated by the review authors based on the mean FU time of the respective treatment groups.

${ }^{\#}$ The study only reported on the FU time in months. Overall: $34 \pm 10$ ( $34 \pm 11$ vs. $\left.33 \pm 12\right)$

$* *$ The study did not adequately report on the enrolment process. Therefore, the loss to follow-up rate could not have been calculated.

${ }^{\dagger \dagger}$ There were significant differences $(\mathrm{p}<0.05)$ between baseline scores and the last follow-up scores after surgery.

${ }_{\ddagger}^{\ddagger}$ The time point was not clearly reported.

${ }^{\S}$ The study reported only on the mean and range of the Lachman test.

IIII $95 \%$ CI was reported: 3.083-3.9200.

१995\% CI was reported: 1.6946-2.4941.

\#\#95\% CI was reported: 2.1028-3.0397.

$* * *$ The time point was not clearly reported.

${ }^{\dagger \dagger}$ The overall IKDC score has 4 qualitative characteristics regarding knee functionality: normal, nearly normal, abnormal, and severely abnormal. In this assessment, only the number of patients with normal and nearly normal characteristics were extracted and summed up.

${ }_{\ddagger \ddagger}^{\ddagger \ddagger}$ Femoral and tibia tunnel enlargements are presented in percentage of the tunnel width at follow-up over the width postoperative in AP view X-ray.

${ }^{\S \S \S}$ Excluding patients with hybrid grafts. The number of patients refers to the analysed patients, not the enrolled ones. 


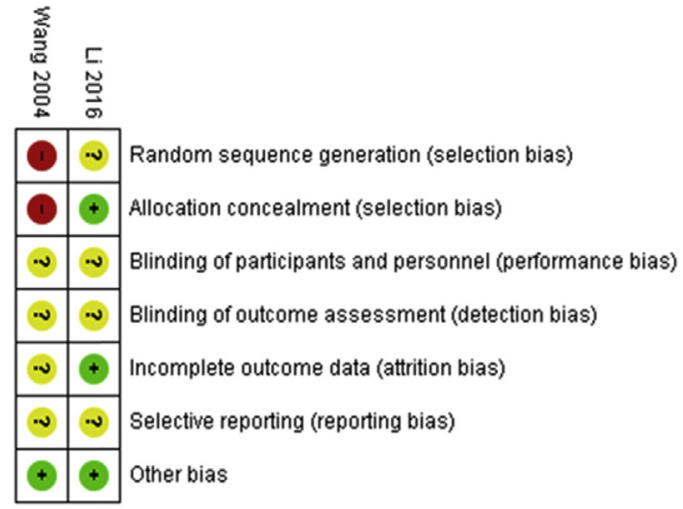

Fig 2. Risk of bias for studies comparing allografts to autografts in PCL reconstruction. This figure was created with the Review Manager, version 5.3 software to summarize the risk of bias at the study level.

reporting of the blinding of participants and the outcomes assessor, resulting in potential bias in the patient-reported outcomes. The risk of detection bias and reporting bias was unclear in both studies; no reporting protocol was published to indicate the complete range of outcomes. It was also unclear whether outcomes assessors were informed of the allocated intervention. The study by Wang et al. ${ }^{26}$ was judged as being at a high risk of bias due to serious limitations in the randomization process. Graft randomization was done according to hospital admission, and the authors also reported issues with allograft availability, resulting in only 23 patients in the allograft group versus 32 in the autograft group. The lack of the allocation concealment resulted in a potential quasi-randomized study classification.

\section{GRADE}

The strength of the evidence in the 2 included studies was assessed according to GRADE ${ }^{22}$; the evidence profile is provided in Table 3 . The strength of the evidence for the effectiveness and safety of allografts compared to autografts in PCL reconstruction was judged as being low to very low. Evidence judged as low according to GRADE indicates that the authors' confidence in the effect estimate is questionable, and the true effect may be substantially different from the estimated effect. If evidence is judged as very low, evidence is either unavailable or does not permit a conclusion. $^{22}$

\section{Results of Studies}

\section{Effectiveness outcome}

The effectiveness of allografts compared to autografts in PCL reconstruction was measured by the crucial outcome of patient-reported function, activity levels and symptoms.
This outcome was measured in both studies by using the following instruments: The Lysholm score analyzed a total of 108 patients (excluding 27 patients with hybrid grafts), including 50 patients in the allografts group and 58 in the autografts group. The mean postoperative Lysholm score in the study by Li et al. ${ }^{25}$ was $85.2 \pm 3.9$ in the allograft group $(\mathrm{n}=27)$ and $87.8 \pm$ 3.6 in the autograft group $(\mathrm{n}=26)$. In the study by Wang et al., ${ }^{26}$ the mean postoperative Lysholm score was $92.3 \pm 6.8$ in the allograft group $(\mathrm{n}=23)$ and $87.8 \pm 9.6$ in the autograft group $(\mathrm{n}=32)$. No statistically significant difference in the mean postoperative Lysholm score was identified between treatment groups $(\mathrm{P}>0.05)$. The results were judged with very low certainty according to the GRADE methodology.

For the Tegner score, a total of 108 patients (excluding 27 patients with hybrid grafts) were analyzed into the allografts group $(\mathrm{n}=50)$ or the autografts group $(\mathrm{n}=58)$. The mean postoperative Tegner score in the study by Li et al. ${ }^{25}$ was reported as $6.2 \pm 1.7$ in the allograft group $(\mathrm{n}=27)$ and $6.8 \pm 1.1$ in the autograft group $(\mathrm{n}=26)$. In the study by Wang et al., ${ }^{26}$ it was reported as $4.7 \pm 1.7$ in the allograft group $(\mathrm{n}=$ 23 ) and $4.7 \pm 1.7$ in the autograft group $(\mathrm{n}=32)$. No statistically significant difference in the mean postoperative Tegner score was identified between the groups $(\mathrm{P}>0.05)$. The results were judged to be of low certainty according to the GRADE methodology.

The subjective IKDC score was reported only in the study by Li et al. ${ }^{25}$ A total of 53 patients (excluding 27 patients with hybrid grafts) were analyzed: the allografts group $(n=27)$ and the autografts group $(n=26)$ group. The mean postoperative subjective IKDC scores were $80.2 \pm 6.8$ and $83.5 \pm 6.3$, respectively. The study did not report a statistically significant difference between the treatment groups $(\mathrm{P}>0.05)$. This result was judged to be of low certainty according to the GRADE methodology.

Clinical knee stability was assessed using the reverse Lachman test, the reverse Pivot shift test and the instrumented side-to-side difference. Both included studies $^{25,26}$ reported on the side-to-side difference in $\mathrm{mm}$. A total of 108 patients (excluding 27 patients with hybrid grafts) were analyzed and placed into the allografts group $(\mathrm{n}=50)$ or the autografts group $(\mathrm{n}=58)$. The study by Li et al. ${ }^{25}$ reported postoperative side-toside differences in $\mathrm{mm}$ of $3.5 \pm 1.1$ and $2.1 \pm 1.0$ in the allograft and autograft group, respectively. A statistically significant difference of $1.4 \mathrm{~mm}(\mathrm{P}<0.001)$ favoring the autografts group, with less side-to-side difference, was reported. This result was judged to be of very low certainty according to the GRADE methodology. The study by Wang et al., ${ }^{26}$ however, reported no statistically significant difference between the groups: $2.8 \pm 1.7$ versus $3.2 \pm 2.6(\mathrm{P}>0.05)$ as measured by the KT-1000 arthrometer. 
Certainty Assessment

\section{Effectiveness}

Patient-reported function,

activity level and symptoms

(follow-up: mean $>2$ years:

assessed with: Lysholm

score)
$2^{1,2,25,26}$

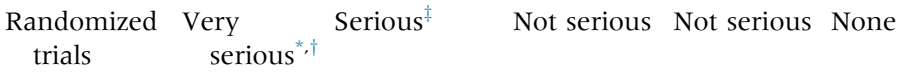

Patient-reported function

activity level and symptoms

(follow-up: mean $>2$ years:

assessed by Tegner score)

$2^{1,2,25,26}$

Randomized Very Not serious Not serious Not serious None

\section{trials}

50

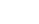

Patient-reported function,

activity level and symptoms

(follow-up: mean 5.6 years:

assessed with: subjective

IKDC score)

$1^{2,25}$

Randomized Serious ${ }^{\dagger}$ Not serious Not serious Serios ${ }^{\S}$ None

trials
58

No

None of the studies found a $\oplus$ Vtatically significant
Very

difference in the

Lysholm score between

treatment groups

postoperatively.

Li et al. ${ }^{25}: 85.2 \pm 3.9$ vs

$87.8 \pm 3.6$, diff. n. $s$.

with $\mathrm{P}>0.05$

Wang et al. ${ }^{26}: 92.3 \pm 6.8$

vs $87.8 \pm 9.6$, diff. n. $s$.

with $\mathrm{P}>0.05$

None of the studies found a $\oplus \oplus \bigcirc \bigcirc \quad$ Critical statistically significant

difference in the Tegner

score between treatment

groups postoperatively.

Li et al. ${ }^{25}: 6.2 \pm 1.7 \mathrm{vs}$

$6.8 \pm 1.1$, diff. n. s. with

$\mathrm{P}>0.05$

Wang et al. ${ }^{26}: 4.7 \pm 1.66$

vs. $4.73 \pm 1.66$, diff. n. $s$.

with $\mathrm{P}>0.05$

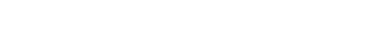


Number of

Certainty Assessment Analyzed Patients*

\begin{tabular}{|c|c|c|c|c|c|c|c|c|c|c|c|}
\hline \multicolumn{7}{|c|}{ Certainty Assessment } & \multicolumn{2}{|c|}{ Analyzed Patients* } & \multirow[b]{2}{*}{ Effect } & \multirow[b]{2}{*}{ Certainty } & \multirow[b]{2}{*}{ Importance } \\
\hline Number of Studies & Study Design & $\begin{array}{l}\text { Risk of } \\
\text { Bias }\end{array}$ & Inconsistency & Indirectness & Imprecision & $\begin{array}{c}\text { Other } \\
\text { Considerations }\end{array}$ & Allograft & Autoraft & & & \\
\hline \multicolumn{12}{|c|}{$\begin{array}{l}\text { Clinical knee stability (follow- } \\
\text { up: mean } 2.8 \text { years assessed } \\
\text { by the Reverse Lachman } \\
\text { test) }\end{array}$} \\
\hline $1^{26}$ & $\begin{array}{l}\text { Randomized } \\
\text { trials }\end{array}$ & $\begin{array}{l}\text { Very } \\
\text { serious* }\end{array}$ & Not serious & Not serious & Not serious & None & 23 & 32 & $\begin{array}{l}\text { The study did not find a } \\
\text { statistically significant } \\
\text { difference in the reverse } \\
\text { Lachman test } \\
\text { postoperatively. } \\
\text { Mean postoperative } \\
\text { reverse Lachman test } \\
\text { score: } \\
0.7 \pm 0.56 \text { vs } 0.75 \pm \\
0.67, \text { diff. n. s. with } \\
P>0.05\end{array}$ & $\begin{array}{l}\oplus \oplus \bigcirc \bigcirc \\
\text { Low }\end{array}$ & Important \\
\hline \multicolumn{12}{|c|}{$\begin{array}{l}\text { Clinical knee stability (assessed } \\
\text { with: Reverse Pivot shift } \\
\text { test) }\end{array}$} \\
\hline $1^{25}$ & $\begin{array}{l}\text { Randomized } \\
\text { trials }\end{array}$ & Serious $^{\dagger}$ & Not serious & Not serious & Not serious & None & 27 & 26 & $\begin{array}{l}\text { Postoperative reverse Pivot } \\
\text { shift (Grade 0-1): } \\
26 / 27(96.3 \%) \text { vs } 26 / 26 \\
(100 \%) \text {, diff. n. s. with } \\
\text { P }>0.05\end{array}$ & $\begin{array}{l}\oplus \oplus \oplus \bigcirc \\
\text { Moderate }\end{array}$ & Important \\
\hline \multicolumn{12}{|c|}{$\begin{array}{l}\text { Clinical knee stability (follow- } \\
\text { up: mean }>2 \text { years; assessed } \\
\text { with: KT arthrometer; better } \\
\text { indicated by lower values) }\end{array}$} \\
\hline $2^{25,26}$ & $\begin{array}{l}\text { Randomized } \\
\text { trials }\end{array}$ & $\begin{array}{l}\text { Very } \\
\text { serious* }\end{array}$ & Serious & Not serious & Not serious & None & 50 & 58 & $\begin{array}{l}1 \text { study found a statistically } \\
\text { significant difference } \\
\text { favoring autografts, } \\
\text { while another study did } \\
\text { not find any statistically } \\
\text { significant difference } \\
\text { based on the side-to-side } \\
\text { difference measured by } \\
\text { an instrumented knee } \\
\text { laxity test. } \\
\text { Side-to-side difference in } \\
\text { mm: } \\
\text { Li et al. }{ }^{25}: 3.5 \pm 1.1 \text { vs } \\
2.1 \pm 1, \text { diff. s. s. with } \\
\text { P }<0.001 \\
\text { Wang et al. }{ }^{26}: 2.83 \pm 1.7\end{array}$ & $\begin{array}{l}\oplus \bigcirc \bigcirc \bigcirc \\
\text { Very low }\end{array}$ & Important \\
\hline
\end{tabular}


Certainty Assessment

\begin{tabular}{|c|c|c|c|c|c|c|}
\hline Number of Studies & Study Design & $\begin{array}{l}\text { Risk of } \\
\text { Bias }\end{array}$ & Inconsistency & Indirectness & Imprecision & Consi \\
\hline \multicolumn{7}{|c|}{$\begin{array}{l}\text { Clinical knee stability (follow- } \\
\text { up: mean }>2 \text { years; assessed } \\
\text { by objective IKDC) }\end{array}$} \\
\hline $2^{25,26}$ & $\begin{array}{l}\text { Randomized } \\
\text { trials }\end{array}$ & $\begin{array}{l}\text { Very } \\
\text { serious }{ }^{*} \dagger\end{array}$ & Not serious & Not serious & Not serious & None \\
\hline
\end{tabular}

Safety

Reoperations (follow-up: mean 5.6 years)

\begin{tabular}{|c|c|c|}
\hline Randomized & Not & Not serious \\
\hline
\end{tabular}

Other

Analyzed Patients*

Effect

Certainty Importance

vs $3.16 \pm 2.6$, diff. n. $s$.

with $\mathrm{P}>0.05$

50

58

None of the studies found

$\oplus \oplus \bigcirc \bigcirc$

Important

statistically significant

Low

difference in the

objective IKDC score

between treatment

groups postoperatively.

Objective IKDC (normal

and nearly normal):

Li et al. ${ }^{25}: 24 / 27$ (88.9\%)

vs $25 / 26(96.2 \%)$

Wang et al. ${ }^{26}: 14 / 23$

$(60.9 \%)$ vs $23 / 32$

$(71.9 \%)$

27

26

The study stated that no

patient needed

additional surgery

because of recurrent or

residual posterior laxity:

$0 \%$ vs $0 \%$ (further

information: NR).

$50 \quad 58$

Overall complication rate (reported in 1 study ${ }^{26}$ ): $0 / 23$ (0) vs $7 / 32$

$(21.9 \%)$.

Infections: Li et $\mathrm{al}^{25}$ : no postoperative infection; Wang et al. ${ }^{26}: 0 / 23(0)$ vs $2 / 32(6.3 \%$;

1 acute and 1 late infection)

Deep venous thrombosis (reported in 1 study $^{25}$ ):

$0 / 27$ (0) vs $0 / 26(0)$

Further reported

complications:

Donor site symptoms in 
$(12.5 \%)$;

Reflex sympathetic

dystrophy in 1 study ${ }^{26}$ :

$0 / 23(0)$ vs $1 / 32(3.1 \%)$

Li et al. ${ }^{25}$ further stated

narratively that no

postoperative infection,

no deep venous

thrombosis, no cases of

major neurovascular

infectious, vascular, deep

venous thrombosis or

wound complications in

any of the 80 analyzed

patients (of whom 27, 26

and 27 received

allografts, autografts and

hybrid grafts,

respectively) occurred.

Tibial and femoral

tunnel enlargement in 1

study $^{26}$ :

Tibial: $12 \pm 20$ (range:

$0-90$ ) vs $12 \pm 14$ (range:

$0-43)$, n. s. with $\mathrm{P}=0.64$

Femoral: $5.3 \pm 22$

(range:

0 -50) vs $13 \pm 19$

(range: 0-55), n. s. with

$\mathrm{P}=0.771$

\section{CI, confidence interval; IKDC, International Knee Documentation Committee; MD, mean difference.}

*In Wang et al., there was high risk of bias for selection bias and unclear risk of bias as to whether patients were blinded.

${ }^{\dagger}$ In Li et al., it was unclear whether the random sequence generation was adequate (selection bias), and whether patients were blinded.

${ }^{\ddagger}$ None of the studies showed any statistically significant differences postoperatively in the Lysholm score between the allograft and the autograft groups. The non-statistically significant differences were not unanimously higher in one treatment group. This may be an indicator for heterogeneity. A calculation of the i-square is further needed to adequately assess how heterogeneous the results for this outcome may be.

${ }^{\S}$ The optimal information size may have not been reached.

"Heterogeneity may have been present because study results were not unanimous. Further calculation of the i-square is needed to elaborate on the extent of the heterogeneity.

The study referred to the patients who did not need additional surgery because of recurrent or residual posterior laxity. It was unclear to the review authors whether this refers to the overall reoperations rate or only the patients with recurrent or residual posterior laxity.

\#The optimal information size may have not been reached. 
The objective IKDC score was reported in both studies. A total of 108 patients (excluding 27 patients with hybrid grafts) were analyzed in the allografts $(n=50)$ or autografts $(n=58)$ groups. No statistically significant difference ( $\mathrm{P}>0.05$ for both groups) in the postoperative objective IKDC score between treatment groups were reported. This result was judged to have low certainty according to the GRADE methodology.

Only the study by Wang et al. ${ }^{26}$ reported on the reverse Lachman test. No statistically significant difference was reported in the mean postoperative reverse Lachman test scores $(\mathrm{P}>0.05)$. This result was judged to have low certainty according to the GRADE methodology.

The reverse Pivot shift test was reported in the study by Li et al. ${ }^{25}$ only. A total of 53 patients (excluding 27 patients with hybrid grafts) were analyzed in the allografts group $(n=27)$ and the autografts group $(n=26)$. No statistically significant difference was reported for the mean postoperative reverse Pivot shift test score $(\mathrm{P}=0.4)$. This result was judged to have moderate certainty according to the GRADE methodology.

None of the studies reported on the health-related quality-of-life scores or the patient-satisfaction scores.

\section{Safety outcome}

The crucial outcomes to evaluate safety were graft failures, reruptures, reoperations and revisions, complications, and procedure-related mortality. The findings are summarized in Table 2. Reoperation was qualitatively reported only in the study by Li et al. ${ }^{25} \mathrm{No}$ quantitative data was reported, and the study stated only that no additional surgery was required as a result of recurrent or residual posterior laxity. This outcome was judged to have low certainty according to the GRADE methodology.

Graft failure, rerupture, revision rates, and procedure-related mortality were not reported in the included studies.

For the overall complications, only the study by Wang et al. ${ }^{26}$ reported that no complications had occurred $(0)$ in the allograft group versus 7 complications $(21.9 \%)$ in the autograft group. This difference was not statistically tested, and the P value was not reported.

Both studies reported on the occurrence of infections. The study by Li et al. ${ }^{25}$ reported no postoperative infections, whereas the study by Wang et al. ${ }^{26}$ reported 2 infections $(6.3 \%)$ in the autograft group. No infections occurred in the allograft group; the difference was not statistically tested, and no $\mathrm{P}$ value was reported. The study by $\mathrm{Li}$ et al. ${ }^{25}$ reported that no deep-vein thrombosis occurred.

Arthrofibrosis, effusion, tenderness, hypoesthesia, and synovitis were not reported in either study.

The study by Wang et al. ${ }^{26}$ reported the occurrence of donor-site symptoms: 0 in the allograft group and
$12.5 \%$ in the autograft group. Reflex sympathetic dystrophy was also reported in $1 / 32$ patients $(3.1 \%)$ in the autograft group versus in $0 / 23$ patients $(0)$ in the allograft group. The differences were not statistically tested, and the the $\mathrm{P}$ value was not reported. The tibial and femoral tunnel widening was also reported, but no statistically significant difference between the allograft and autograft groups were found $(\mathrm{P}=0.640 ; \mathrm{P}=$ $0.771)$.

The study by Li et al. ${ }^{25}$ reported no cases of major neurovascular, infectious, vascular, or wound complications and, overall, the outcome of complications was judged to have low certainty according to the GRADE methodology.

\section{Discussion}

The results of this study suggest that allografts and autografts may be comparable in PCL reconstruction regarding the crucial effectiveness outcome of patientreported function, activity level and symptoms. No statistically significant postoperative differences were reported between allografts and autografts for the Lysholm scale, the Tegner score, the subjective IKDC scores, or knee stability. The evidence base consisted of only 2 RCTs with unclear to high risk of bias and inconsistency and heterogeneity of reported outcomes and various graft sources. This is in line with results published in other systematic reviews ${ }^{14,27-29}$; however, the certainty and strength of the evidence was judged according to the GRADE methodology only in this review. The overall strength of this evidence was judged to be low to very low, highlighting the limited confidence in reported effects estimates because the true effects might be substantially different from the estimated effects. Caution in interpretation of the results from the primary studies is, therefore, recommended.

The study by Li et al. ${ }^{25}$ reported a statistically significant difference of $1.4 \mathrm{~mm}(\mathrm{P}<0.001)$ favoring the autografts group; there was less side-to-side difference as measured by instrumented anteroposterior laxity. It was judged with a very low certainty of the evidence according to the GRADE. This, however, was not reported in the study by Wang et al., ${ }^{26}$ which used the KT-1000 arthrometer to measure PCL laxity. The authors did, however, report a qualitative mild to moderate laxity in about $25 \%$ of patients in both the allografts and the autografts groups. The result should be interpreted with caution because there is potential inconsistency in the way the outcome was measured, and there exists the risk of reporting bias and heterogeneity of the graft types. The reported statistical mean difference was small, and the clinical relevance ${ }^{30}$ is questioned due to the lack of a predefined, minimal clinically important difference (MCID) in PCL reconstruction. ${ }^{14,15}$ A difference from the contralateral healthy side of less than $3 \mathrm{~mm}$ is considered normal; a 
range from 3 to $5 \mathrm{~mm}$ is considered a gray zone; and a difference greater than $5 \mathrm{~mm}$ is considered to be a pathologic value regarding laxity due to anterior cruciate ligament ruptures. ${ }^{31-33}$ It is, therefore, not plausible that a value smaller than $3 \mathrm{~mm}$ is a clinically relevant difference regarding the $\mathrm{PCL}$, as outlined in the study by Li et al. ${ }^{25}$ Patients might be less likely to report subjective instability or functional disability because the knee might be perceived as being stable as a result of the muscle support during functional activities. This might explain the reported success with conservative treatment for grade I and II PCL injuries due to the strong focus on physical rehabilitation. Autograft is well known for donor-site morbidity and concern for weakening the extensor and flexor mechanisms, ${ }^{2}$ yet only the study by Wang et al. ${ }^{26}$ reported the measurement of isokinetic quadriceps and hamstring muscle strength and endurance. Postoperative concentric and eccentric muscle strength and endurance deficits were reported for both groups, but no statistically significant difference was found between the postoperative allograft and autograft scores. ${ }^{26}$ The preoperative values were not provided; comparisons were made to the uninjured side. The quantitative measurement of pre- or postoperative muscle strength was not reported or discussed as an outcome in other relevant studies. Perhaps adequate muscle strength and endurance have a more critical role to play and warrant further investigation and debate in the light of the increased risk of osteoarthritis development after PCL injury. ${ }^{1}$

Certain population subgroups such as high-level athletes ${ }^{9}$ might also be more vulnerable to muscle weaknesses following autografts and would benefit from specific, unbiased and well-designed studies.

One systematic review reported a higher level of postoperative activity in favor of autografts. ${ }^{34}$ Some reviews reported no significant differences in postoperative functional outcomes using autografts compared to allografts, ${ }^{14,15}$ whereas another metaanalysis reported insufficient evidence to report the superiority of allografts over autografts due to poor quality and data availability. ${ }^{27,28}$

This review distinguishes the safety outcomes of PCL reconstruction from the effectiveness outcomes and suggests that there is insufficient evidence to judge superiority or inferiority of a particular graft type. It emphasizes poorly measured and reported complications because none of the primary studies reported on graft failure rates or revision or rerupture rates despite the reported graft failure rates of $11.6 \%$ and $12.6 \%$ mentioned in other studies. ${ }^{5,6}$ Only the study by Wang et al. $^{26}$ reported on an overall complication rate but without statistical testing. It seems that the reported complications are related to graft harvesting and do not capture all relevant complications. The study ${ }^{26}$ also reported that allografts lead to fewer complications related to infections, donor-site pain and reflex sympathetic dystrophy in comparison to autografts. However, it was not reported how this was measured, nor was any statistical testing performed. It is also the only study to report that the femoral and tibial tunnels were comparable and that there was no statistically significant difference between the allografts and autografts. That is not mentioned in the other systematic reviews, despite its being indicated as a reason for graft failure. ${ }^{7,8}$ Y-irradiated allografts were included in the primary study by $\mathrm{Li}$ et al. ${ }^{25}$ The authors acknowledged the limitations of this graft type, such as disease transmission, longer remodeling times and graft integration in the tunnels, as mentioned in other reviews. ${ }^{2,11,12}$ However, the main focus of this review was on measuring the stability outcomes and safety measures, such as no additional surgery needed due to posterior laxity, no cases of major infections and no vascular or wound complications, which were poorly measured and reported. No statistical testing was performed on group results, and a low GRADE judgment suggests caution in judging these findings because they might be substantially different from the true results.

The body of best evidence would benefit from future research focusing on studies using standardized, objective effectiveness- and safety-outcome measures, comparison with 1 type of graft only and methodologically sound, randomized study designs in PCL reconstruction. ${ }^{28}$

\section{Limitations}

The primary limitation of this review is the inclusion of only 2 studies, which had a relatively small number of patients and a high risk of assessment bias (Fig 2). The studies reported a range of different allogenic graft types, such as y-irradiated, fresh-frozen and 4-stranded allografts and hamstring or quadriceps autografts. The extent of the potential effects of the differences and various disinfection procedures on clinical outcomes was unclear because each graft option presents unique characteristics that might affect the generalizablility of the comparison results. There is also poor reporting of complications, such as graft failures and reruptures resulting in variation, and there is heterogeneity in the reported outcomes, reflecting the lack of consensus on the criteria defining successful outcomes after PCL reconstruction. This resulted in the inability to pool results and, therefore, no meta-analysis could be performed. An MCID was not defined for the instrumented anteroposterior laxity measurement. Such a definition could be beneficial and would enable better judgment as to whether statistically significant differences found for objective, instrumented laxity outcomes are also clinically relevant ${ }^{30}$ in practice. 


\section{Conclusions}

Allografts may be comparable to autografts for crucial effectiveness outcomes, but insufficient evidence was found to judge crucial safety outcomes due to poor reporting of safety measures and outcomes. Results should be interpreted with caution because there is a lack of good-quality evidence to support the superiority of allografts over autografts; there is a high risk of bias in the primary studies and, overall, very low strength of the body of evidence according to the GRADE.

\section{Acknowledgments}

Project support by Information specialist: Tarquin Mittermayr, B.A. (Hons), M.A.

\section{References}

1. Sanders TL, Pareek A, Barrett IJ, et al. Incidence and longterm follow-up of isolated posterior cruciate ligament tears. Knee Surg Sports Traumatol Arthrosc 2017;25: 3017-3023.

2. Johnson P, Mitchell S, Görtz S. Graft considerations in posterior cruciate ligament reconstruction. Current Rev Musculoskel Med 2018;11:521-527.

3. MacDonald J, Rodenberg R. Posterior cruciate ligament injury. UpToDate, 2018, https://www.uptodate.com/ contents/posterior-cruciate-ligament-injury.

4. Wang D, Graziano J, Williams RJI, Jones KJ. Nonoperative treatment of PCL injuries: Goals of rehabilitation and the natural history of conservative care. Curr Rev Musculoskel Med 2018;1 1:290-297.

5. Hammoud S, Reinhardt KR, RG M. Outcomes of posterior cruciate ligament treatment: A review of the evidence. Sports Med Arthrosc Rev 2010;18:280-291.

6. Tucker CJ, Cotter EJ, Waterman BR, et al. Functional outcomes after isolated and combined posterior cruciate ligament reconstruction in a military population. Orthop $J$ Sports Med 2019;7:23259671198751392325967119875139.

7. Noyes FR, Barber-Westin S. Posterior ligament revision reconstruction, partl: Causes of surgical failure in 52 consecutive operations. Am J Sports Med 2005;33:646-654.

8. Zawodny S, Miller M. Complications of posterior cruciate ligament surgery. Sports Med Arthrosc Rev 2010;18: 269-274.

9. Devitt BM, Dissanayake R, Clair J, et al. Isolated posterior cruciate reconstruction results in improved functional outcome but low rates of return to preinjury level of sport: A systematic review and meta-analysis. Orthopead J Sports Med 2018;6:2325967118804478.

10. Hoher J, Scheffler S. Graft choice and graft fixation in PCL reconstruction. Knee Surg Sports Traumatol Arthrosc 2003;11:297-306.

11. Friedberg R. Anterior cruciate ligament injury. UpToDate, 2018.

12. Hudgens JL, Gilette BP, Krych AJ, et al. Allograft versus autograft in posterior cruciate ligament reconstruction: An evidence-based sytematic review. J Knee Surg 2013;26: 109-115.
13. Fahey M, Indelicto PA. Bone tunnel enlargement after anterior cruciate ligament replacement. Am J Sports Med 1994;22:410-414.

14. Ansari AS, Dennis BB, Horner NS, et al. Influence of graft source on postoperative activity and joint laxity in posterior cruciate ligament reconstruction: A systematic review. Arthroscopy 2018:262-274.e266.

15. Belk JW, Kraeutler MJ, Purcell JM, McCarty EC. Autograft versus allograft for posterior cruciate ligament reconstruction: An updated systematic review and metaanalysis. Am J Sports Med 2018;46:1752-1757.

16. Zeng C, Gao SG, Li H, et al. Autograft versus allograft in anterior cruciate ligament reconstruction: A meta-analysis of randomized controlled trials and systematic review of overlapping systematic reviews. Arthroscopy 2016;32: 153-163.el18.

17. European Network of Health Technology Assessment (EUnetHTA) Joint Action 2 WP. HTA Core Model version 3.0 (pdf). 2016.

18. Liberati A, Altman DG, Tetzlaff J, et al. The PRISMA statement for reporting systematic reviews and metaanalyses of studies that evaluate health care interventions: Explanation and elaboration. J Clin Epidemiol 2009;62:el-e34.

19. Moher D, Liberati A, Tetzlaff J, Altman DG. Preferred reporting items for systematic reviews and meta-analyses: The PRISMA statement. Int J Surg 2010;8:336-341.

20. Goetz G, De Villiers C. Allograft for anterior and posterior cruciate ligament reconstruction: Systematic review. Decision support document 116. LBI-HTA 2019.

21. European Network of Health Technology Assessment Joint Action 2 WP. Levels of evidence: Internal validity of randomised controlled trials 2015.

22. Guyatt G, Oxman AD, Akl EA, et al. GRADE guidelines: 1. Introduction-GRADE evidence profiles and summary of findings tables. J Clin Epidemiol 2011;64: 383-394.

23. Hohmann E, Feldman M, Hunt TJ, et al. Research pearls: How do we establish the level of evidence? Arthroscopy 2018;34:3271-3277.

24. Higgins JPT, Altman DG, Gøtzsche PC, et al. The Cochrane Collaboration's tool for assessing risk of bias in randomised trials. BMJ 2011;343:d5928.

25. Li J, Kong F, Gao X, Shen Y, Gao S. Prospective randomized comparison of knee stability and proprioception for posterior cruciate ligament reconstruction with autograft, hybrid graft, and gamma-irradiated allograft. Arthroscopy 2016;32:2548-2555.

26. Wang CJ, Chan YS, Weng LH, et al. Comparison of autogenous and allogenous posterior cruciate ligament reconstructions of the knee. Injury 2004;35: 1279-1285.

27. Tian $\mathrm{P}, \mathrm{Hu} \mathrm{W}, \mathrm{Li} \mathrm{Z}$, et al. Comparison of autograft and allograft tendons in posterior cruciate ligament reconstruction: A meta-analysis. Medicine (Baltimore) 2017;96: e7434.

28. Martin RK, Levy BA. Editorial commentary:What is the best graft source for postreior cruciate ligament reconstruction? Arthroscopy 2018;35:275-276.

29. Lee YS, Lee SH, Lee OS. Graft sources do not affect to the outcome of transtibial posterior cruciate ligament 
reconstruction: A systematic review. Arch Orthop Trauma Surg 2018;138:1103-1116.

30. Dhawan A, Brand JC, Provencher MT, et al. Research pearls: The significance of statistics and perils of pooling. Arthroscopy 2017;33:1099-1101.

31. Huber FE, Harner C, Lephart S. Intratester and intertester reliability of the KT-1000 arthrometer in the assessment of posterior laxity of the knee. Am J Sports Med 1997;25:479-485.

32. Daniel DM, Stone ML, Sachs R. Instrumented measurement of anterior knee laxity in patients with acute anterior cruciate ligament disruption. Am J Sports Med 1985;13:401-407.

33. Anderson A, Snyder R, Federspiel C, Lipscomb A. Instrumented evaluation of knee laxity: A comparison of five arthrometers. Am J Sports Med 1992;20:135-140.

34. Liang Chen YW, Yufeng Wu, Dawei Gao, Guoping Xie. Autografts promote post-operative activity level compared to allografts in posterior cruciate ligament reconstruction: A systematic review and meta-analysis. Int J Clin Exper Med 2017;10:9807-9817. 